\title{
Psychological Intervention to Modify Anxiety, Depression and Quality of Life in Patients with an Implantable Pacemaker
}

\author{
Carlos Figueroa, Luis Alcocer, Bertha Ramos \\ National University of Mexico, Mexico City, Mexico \\ Email: carlos.figueroa@itesm.mx, alcocerdb@gmail.com, becaau@yahoo.com \\ Received 18 January 2016; accepted 21 March 2016; published 24 March 2016 \\ Copyright $@ 2016$ by authors and Scientific Research Publishing Inc. \\ This work is licensed under the Creative Commons Attribution International License (CC BY). \\ http://creativecommons.org/licenses/by/4.0/

(c) (i) Open Access

\begin{abstract}
The objective was to determine the effectiveness of a psychological intervention program for the management of anxiety and depression for patients with potentially lethal cardiac arrhythmia with a portable pacemaker. 11 patients from the Cardiology General Hospital of Mexico were evaluated. Cognitive behavioral intervention was conducted once a week for six weeks, for the management of anxiety and depression. The results showed $45.5 \%$ depression in patients that was reduced to $9.1 \%$ after the treatment, similar situation with anxiety that decreased to $45.5 \%$ compared to the initial psychological evaluation of 81.8\%. The different factors of Health Related Quality of Life also were improved after the psychological treatment. It is suggested the necessity to identify and treat psychologically the emotional comorbidity of these patients.
\end{abstract}

\section{Keywords}

Anxiety, Depression, Psychological Intervention, Cardiac Arrhytmia

\section{Introduction}

According to the World Health Organization (WHO, 2011) in 2030, about 23.6 million people in the world will die from cardiovascular disease, particularly heart attacks and strokes, often associated with risk factors such as smoking, sedentary lifestyle and an unhealthy diet. In the period January-March 2011, more than 6700 people attended their first cardiology consultation to the Hospital General of Mexico. Electrical rhythm conductance disruptions in heart rate and adjustment assistance of pacemakers were found among the eleven reasons for vi-

How to cite this paper: Figueroa, C., Alcocer, L., \& Ramos, B. (2016). Psychological Intervention to Modify Anxiety, Depression and Quality of Life in Patients with an Implantable Pacemaker. Psychology, 7, 374-381. 
siting the cardiology service (General Hospital of Mexico, 2011). However, rather than reduced, as it was an established goal in the health politics plan of the Secretaria de Salud to the beginning of the last presidential term, the ischemic heart disease mortality continues to grow in Mexico. In 2006, Secretaria de Salud planned to reduce cardiovascular mortality by 15 percent, but contrary to what was planned, mortality grew 15 percent in 2010 (National Insitute of Public Health, 2010; Secretaria de Salud, 2012).

Cardiac arrhythmias are among many cardiovascular diseases. They are defined as disturbances in the normal rhythm of the heart, and are produced in response to common physiological needs or due to disruptions in the heart's electrical activity governing the contraction of the heart muscle. Brady arrhythmia is a term used to refer to a cardiac rhythm with a frequency of less than 60 beats per minute, although it is not a lethal rhythm and can be easily monitored, for example, in athletes. This rhythm is considered pathological only if it is accompanied by symptoms and/or with a frequency of less than 40 beats per minute, it is caused as a result of diseases affecting the sinus node, atrioventricular node, the His-Purkinje system or disruptions combined in those nodes (Matiz, Gutierrez, Duke, \& Gómez, 1999).

As part of surgical treatment, an electronic pacemaker is implanted near the collarbone. Arowne \& Villeda (2000) mentioned that the pacing function is to monitor heart rate and to transmit unperceptible painless electrical pulses to the right ventricle of the heart to start each beat only when necessary. Such device is needed if the heart beats too slowly and the problem cannot be controlled with medication alone.

\section{Psychosocial Factors Associated with Cardiac Arrhytmia}

Anxiety and depression cause not only physiological changes in platelet function and blood coagulation but also autonomic disbalance. For example, sympathetic hyperactivity is associated to an increase in resting heart rate, baroreflex sensitivity dysfunction and alteration of ventricular repolarization. These last two conditions predict fatal or life-threatening arrhythmias and sudden cardiac death (Esquivel et al., 2009).

Leosdottir et al. (2006) found anxiety in more than 30\% of patients with cardiac arrhythmia (with pacemaker or implantable defibrillator). In another study with 42 patients with cardiac arrhythmia, anxiety was found in $46 \%$ of the sample (Kaya et al., 2006). In a documented research at the Hospital General de Mexico, 27.9\% pacemaker patients reported having moderate or severe anxiety (Sarmiento, 2011). Prospective studies indicate that anxiety has a negative impact on the course of heart disease (severity, mortality, recurrence) and this influence appears independently from the effects of depression, which is another highly correlated psychological variable with heart disease. Although anxiety is commonly reported among cardiac patients, only one in three patients are asked about these symptoms (Zvolensky \& Smits, 2008). It was found that some arrhythmias occur more frequently in periods where the patient reported anxiety. For example, Blatt (2004) found that in 11 out of 16 episodes of arrhythmias there was increased heart disease.

In pacemaker patients reporting anxiety, the attributed cause is fear of malfunction of the device and the feelings of helplessness due to dependence on the device, and changes in lifestyle that the patient will have to face (Ackley \& Ladwig, 2007). In another study Duru et al. (2001) corroborated these findings. They found that patients with a cardiac arrhythmia with an implantable device perceive it as an "extension of their life". However, their anxiety was associated with technical problems and device battery depletion.

Anxiety also affects lifestyle, and high levels of it are correlated to unhealthy diets, smoking, alcohol or drug consumption, therapeutic noncompliance, sleep problems and sedentary lifestyle. Some authors further elaborate on the issue. According to Moser \& De Jong (2006) these risks factors are also concomitantly associated to the incidence and cardiac disease progression.

Another psychosocial factor associated to cardiac arrhythmias is depression.

Kaya et al. (2006) and Sarmiento (2011) (in México), respectively, reported 41\% and 30.7\% prevalence of depression in these patients.This state is characterized by loss of interest in pleasurable activities, feelings of guilt or worthlessness, decreased energy, difficulty in concentrating or making decisions, problems, sleep and appetite disturbances, irritability and, in some cases, thoughts of suicide (Parmet, Lynm, \& Glass, 2002). These patients, as well as the anxiety prone, tend to perform risky behaviors, such as excessive consumption of alcohol and tobacco, exhibit physical inactivity leading to the appearance of clinical issues, such as obesity. This condition might favor the development of the cardiovascular disease or the severity of symptoms that contribute to the presence of hypertension, insulin resistance, diabetes as well as non-adherence (DiMatteo, Lepper, \& Croghan, 2000). 
Another construct that it is crucial to understanding the impact of emotional comorbidity in the course of heart disease is health related quality of life (HRQOL). It refers how the patient's symptoms and their subsequent therapy affects their ability to perform physical and social activities (Ittersum, Greef, Gelder, Coster, Brugemann, \& Schans, 2003; Coelho, Ramos, Prata, Bettencourt, \& Ferreira, 2005; García \& Calvanese, 2008). Cardiac arrhythmia patients with an implantable device account for lower perceived HRQoL as a consequence of several concerns related to the functioning of the device, and reports psychological comorbidity (depression and anxiety) related to change of body image and life style, limitations in daily activities and physical discomfort (Duru et al., 2001).

Sarmiento (2011) found that 7.9\% of pacemakers cardiac patients and $12.9 \%$ of heart failure patients reported low HRQOL in The Kansas City Quality of Life Questionnaire at the Hospital General of Mexico. Furthermore, Martijn et al. (2008a, 2008b) found in 818 pacemaker implanted patients significantly lower HRQOL compared to general population $(\mathrm{p}<0.001)$. Patients with pacemaker were compared before the implant and 1 year after having the device placed, finding a better HRQOL in patients who already had a year with the implant. Age and cardiac comorbidities were categorized to as predictors of better HRQOL.

Behavioral Cardiology is the field in Psychology which focuses on the psychological assessment and intervention for cardiovascular patients (Clay, 2007). Its goal is to investigate behavioral psychosocial factors that favor the occurrence and development of cardiovascular disease. This line of investigation encompasses primary and secondary prevention and rehabilitation of cardiac patients, while giving support in the diagnosis and multidisciplinary intervention for prevention and control of cardiovascular disease (Figueroa, Dominguez, Ramos, \& Alcocer, 2009). Namely, cognitive behavior therapy is used to help patients overcome their maladaptive behaviors, thoughts and emotions in a few sessions (Ellis \& Abrams, 2005). By promoting compliance toward realistic therapeutic goals and the adequate coping of cardiovascular risk factors, cognitive restructuring training in coping skills and problem solving techniques are the most effective techniques for changing emotional comorbidity according to Arrivillaga, Varela, Cáceres, Correa, \& Holguin (2007). As well, techniques such as training in assertive communication, biofeedback, relaxation therapy and psychoeducation are effective for controlling psychosocial cardiovascular risk factors (Arrivillaga et al., 2007).

Psychoeducation is a therapeutic approach used to provide the family and the patient with detailed information about the disease, the device and how to improve quality of life. Education is a process of acquiring skills, techniques and short-term behaviors that allow the patient, family and those who interact with him cope with disease maladjustment. It implies objective and comprehensive knowledge about a specific topic in the following dimensions: biological (knowledge about the disease, treatment, adherence to treatment, relapse prevention), psychological (emotional and behavioral implications of the disease, changes in family dynamics, impact in lifestyle from the psychological consequences), and social (re-entry into society, strengthening social support, integration into social groups). Psychoeducation has several goals: it decreases the overall load derived from the disease, it improves the quality of life, it helps to effectively cope with the disease, it decreases ambivalence in making decisions, it diminishes psychological stress and anxiety, it increases self-efficacy and the perception of responsibility while it actively involves the patient in health care and treatment (Morillo, Medina, Roses, \& Cabrales, 2005).

\section{Method}

Objective: To determine the effectiveness of a psychological intervention program for the management of anxiety and depression in pacemaker cardiac arrhythmia patients.

Design: Pre-experimental.

Setting: Behavioral Cardiology Unit, at the Hospital General of Mexico.

Participants:

- 11 out-patients with potentially lethal cardiac arrhythmia were randomly selected from those who attended to the Hospital General de Mexico and completed the psychological questionnaires.

- Three health psychologists to conduct psychological assessments and interventions.

- A cardiologist to monitor the medical status of the patients.

Instruments:

- Informed Consent Letter: A document by which the patient is requested approval to participate in the project, explaining the goal and the activities carried out in the study emphasizing the confidentiality of the informa- 
tion provided.

- Identification form: it asked for demographic data, time of pacemaker implantation, and questions about patient's perception of health status.

- Kansas City Cardiomyopathy Questionnaire (Green, Porter, Bresnahan, \& Spertus, 2000) is a 23-item questionnaire, self-administered that measures physical function, symptoms (frequency, severity, and recent changes), social functioning, self-efficacy and quality of life. It gives a score from 0 to 100 , higher scores are associated with better HRQOL.

- Hospital Anxiety Depression Scale (Zigmond \& Snaith, 1983). A 14-item self-administered questionnaire composed of two subscales, one for anxiety (items odd) and one for depression (items evens). The scale omits the inclusion of physical symptom items that can be confused by patients with symptoms characteristic of their physical illness. The intensity or frequency of the symptom is rated on a Likert scale of 4 points (range: 0 - 3) which was answered considering the information of the last 7 seven days.

Procedure

It consisted in 6 sessions ( 2 sessions for pre and post evaluation phase, 4 sessions for cognitive behavioral intervention program), once a week, 60 minutes each (sesión), divided into three phases:

Phase 1 (Evaluation):

Session 1

Patients were admitted in the study after reading and signing the informed consent letter. Then they were given a battery of psychological tests containing:

- Identification Sheet,

- Kansas City Cardiomyopathy Questionnaire,

- HADS Questionnaire.

Phase 2 (Cognitive behavioral intervention program):

Session 2

For greater understanding of the illness, psychoeducation was given to the patients providing information about: functioning of the heart, definition of a cardiac arrhythmia, functioning of a pacemaker and risk factors associated with the disease. At the end of the session, they were provided with three brochures containing information related to these issues. For homework, patients were instructed to read them and to give comments and opinions at the beginning of the following session.

Session 3

Psychoeducation encompassed information about how depression, anxiety, as well as a risky lifestyle (smoking, alcohol, diet, physical activity) bias in the origin, maintenance and exacerbation of the disease.

Session 4

The goal was to increase patient's awareness of the relation between risky or healthy behavior and heart condition. Patients were encouraged to talk about these issues and to express doubts in order to decrease anxiety or depression. As well, patients were taught the cycle of diaphragmatic breathing and progressive relaxation techniques as practical strategies to manage stress and anxiety. They were also encouraged to practice these techniques daily. Three more brochures were given for personal use containing information about electrons, pacemaker monitoring and pacemaker electromagnetic interference.

Session 5

Patients commented on the information about the last brochures and doubts were sorted by the therapist. All the strategies learned in the last sessions (psychoeducation, diaphragmatic breathing and progressive relaxation techniques) were summarized. Patients were encouraged to incorporate this learning in their everyday life in order to efficiently manage the emotional comorbidity associated to cardiovascular disease.

Phase 3 (post-evaluation):

Session 6

This session was similar to session 1 . Patients were given the battery of psychological tests without the consent letter.

\section{Statistical Analysis}

Descriptive statistics were done to determine the socio-demographic characteristics of the patients. Student's test was used to assess differences in scores on the psychological variables as a result of the psychological interven- 
tion.

\section{Results}

The sociodemographic results of the 11 patients showed a mean age of 64.18 years (range minimum 27 and maximum 87 years), 54.5\% $(n=6)$ males and $45.5 \%(n=5)$ females, $45.5 \%(n=5)$ married or cohabiting, the predominant occupation is housewife with $45.5 \%(\mathrm{n}=5)$, and most patients had primary education $54.5 \%(\mathrm{n}=6)$ (see Table 1).

The depression reported in the HADS subscale showed that it decreased. In the pre-evaluation $45.5 \%$ of patients had depression, but in post-evaluation only 9.1\% reported depressive symptoms (see Table 2).

In the case of HADS Anxiety subscale, $81.8 \%$ of patients experienced anxiety in the pre-assessment, and it decreased in the phase of post-evaluation $45.5 \%$ of patients (Table 3 ).

The results of the post-evaluation of the Health Related Quality of Life scale showed clinical differences in the following areas: Physical Limitations, Symptoms Frequency, Symptoms Severity, Self-efficacy, Quality of Life, and Clinical Summary, Statistically significant differences were found in the areas of Symptoms $(\mathrm{Z}=$ $-2.20, p=0.02), b)$ and Symptoms Changes Over Time $(Z=-2.38, p=0.01)$. The social interference area did not change between pre and post-evaluation (see Table 4).

Table 1. Sociodemographic characteristics of patients with pacemaker.

\begin{tabular}{|c|c|c|c|c|}
\hline & $\bar{X}$ & St. Dev. & $\%$ & $\mathrm{~N}$ \\
\hline Age & 64.18 & 17.94 & & 11 \\
\hline \multicolumn{5}{|l|}{ Gender } \\
\hline Male & & & 54.5 & 6 \\
\hline Female & & & 45.5 & 5 \\
\hline \multicolumn{5}{|l|}{ Occupation } \\
\hline Student & & & 9.1 & 1 \\
\hline Employee & & & 9.1 & 1 \\
\hline Housewife & & & 45.5 & 5 \\
\hline Informal job & & & 36.4 & 4 \\
\hline \multicolumn{5}{|l|}{ Civil Status } \\
\hline Single & & & 45.5 & 5 \\
\hline Married or F.U. & & & 45.5 & 5 \\
\hline Widow & & & 9.1 & 1 \\
\hline \multicolumn{5}{|l|}{ Schooling } \\
\hline Can read and write & & & 18.2 & 2 \\
\hline Primary & & & 54.5 & 6 \\
\hline Secondary & & & 9.1 & 1 \\
\hline High school & & & 9.1 & 1 \\
\hline Professional & & & 9.1 & 1 \\
\hline
\end{tabular}

Note. F.U.: Free Union:

Table 2. Comparison of depression in the pre-post evaluation HADS questionnaire.

\begin{tabular}{ccccc} 
& \multicolumn{2}{c}{ Pre evaluation } & \multicolumn{2}{c}{ Post evaluation } \\
\cline { 2 - 5 } & $\%$ & (n) & $\%$ & (n) \\
\hline No present & 54.5 & $(6)$ & 90.9 & (10) \\
Present & 45.5 & $(5)$ & 9.1 & (1) \\
\hline
\end{tabular}


Table 3. HADS questionnaire. Anxiety comparison in the pre-post evaluation.

\begin{tabular}{ccccc}
\hline & \multicolumn{2}{c}{ Pre evaluation } & \multicolumn{2}{c}{ Post evaluation } \\
\cline { 2 - 5 } & $\%$ & (n) & $\%$ & (n) \\
No present & 18.2 & $(2)$ & 54.5 & $(6)$ \\
Present & 81.8 & $(9)$ & 45.5 & (5) \\
\hline
\end{tabular}

Table 4. Comparison of HRQOL in the pre-post evaluation in the Kansas City cardiomyopathy questionnaire.

\begin{tabular}{|c|c|c|c|c|c|c|c|}
\hline & \multirow{2}{*}{$\mathrm{N}$} & \multirow{2}{*}{$\mathrm{Z}$} & \multirow{2}{*}{ Sig. } & \multicolumn{2}{|c|}{ Pre-evaluation } & \multicolumn{2}{|c|}{ Post-evaluation } \\
\hline & & & & M & Des. St & M & Des. St \\
\hline Physical limitations & 11 & 0.000 & 1.000 & 66.9673 & 14.4889 & 67.5727 & 9.89856 \\
\hline Symptoms & 11 & -2.201 & 0.028 & 86.7709 & 13.7734 & 96.4173 & 7.99981 \\
\hline Symptoms frequency & 11 & -0.954 & 0.340 & 93.1818 & 9.03749 & 96.5909 & 8.08337 \\
\hline Symptoms severity & 11 & -1.069 & 0.285 & 90.9082 & 20.2271 & 97.7264 & 5.39056 \\
\hline Symptoms changes over time & 11 & -2.388 & 0.017 & 56.3636 & 32.0227 & 92.7273 & 18.48833 \\
\hline Self-efficacy & 11 & -1.071 & 0.284 & 72.7236 & 16.7056 & 81.0555 & 12.95755 \\
\hline Quality of life & 11 & -0.784 & 0.433 & 77.0009 & 11.8970 & 80.7445 & 11.18805 \\
\hline Social Interference & 11 & -1.414 & 0.157 & 83.6364 & 8.09040 & 80.0000 & 0.00000 \\
\hline Functional Status & 11 & -1.304 & 0.192 & 78.2391 & 7.94774 & 81.8136 & 6.78198 \\
\hline Clinical Summary & 11 & -0.979 & 0.328 & 78.5591 & 6.46021 & 80.8509 & 7.02205 \\
\hline
\end{tabular}

\section{Discussion}

Clinically and statistically significant differences were found as a result of the psychological intervention program for the management of anxiety and depression in pacemaker cardiac arrhythmia patients.

Clinical positive changes were found in the areas of anxiety and depression. Regarding HRQoL, clinical differences were shown in almost all dimensions, and in the dimensions (symptoms and symptoms change over time) changes were statistically significant.

The result of this investigation is a clear indication of cognitive behavior therapy being effective in cardiac populations. Like patients with other cardiac problems, arrhythmia patients with pacemaker can benefit from understanding the role that psychological factors play in their ability to manage their illness. Providing disease and psychological information is a key to providing care for arrhythmia patients, and when the provider can conceptualize and describe the specific interaction among the medical, psychological, social, and behavioral factors in arrhythmia disease, patients are on the way toward coping better with their symptoms. A patient with a proficient understanding of their symptoms allows communication of needs, especially when interacting with healthcare providers. Furthermore, education is an important psychosocial risk-reducing and quality of life-improving strategy, as patients gain greater insight into the interplay between psychological symptoms and the perception of symptoms of the disease.

Feelings of depressed mood or anxiety can lead to feelings of lack of control of the management of the disease (Van den Broek, Nyklíček, Van der Voort, Alings, Meijer, \& Denollet, 2009; Whang, Kubzansky, Kawachi, Rexrode, Kroenke, Glynn, Garan, \& Albert, 2009). To break the cycle, a deliberate plan is needed in which the patient schedules pleasant events and has tools to help gain some control over thoughts and physiological reactivity to distress. Diaphragmatic breathing is often a first line of defense when combating anxiety and controlling autonomic arousal.

Most arrhythmia patients experience at least some periods of fear and depression (Watkins, Blumenthal, Davidson, Babyak, McCants, \& Sketch, 2006). Merely discussing the facts about the disease can help to rectify false beliefs and unrealistic cognitions. Sometimes, the only medicine needed is knowledge. For many patients, thoughts about their condition continue to be exaggerated and inconsistent from the reality of their condition. When negative automatic thoughts are present, patients must actively confront these thoughts and try to replace 
them with cognitions that are more realistic. Patients who have a clear plan for managing distress and managing their disease are more likely to feel empowered and think clearly during a real emergency.

This article serves as a rationale for screening and providing treatment for the psychological symptoms in patients with arrhythmia disease.

Limitations of the study: the sample size does not allow the generalization of these results to other cardiovascular diseases. A follow-up evaluation is necessary to determine the permanence of the results over time.

Directions for future research: more institutional protocols that include psychological evaluation and intervention to manage emotional comorbidity of different cardiovascular disease (e.g., heart failure patients) should be developed.

\section{References}

Ackley, B., \& Ladwig, G. (2007). Manual of Nursing Diagnoses. España: Elsevier Mosby.

Arowne, C., \& Villeda, A. (2000). Permanent Cardiac Pacemakers. Revista Médica Honduras, 68, 96-101.

Arrivillaga, Q., Varela, A., Cáceres, R., Correa, S., \& Holguin, P. (2007). Effectiveness of a Cognitive Behavioral Program for Reducing Levels of Blood Pressure. Pensamiento Psicológico, 3, 33-49.

Blatt, C. (2004). Anxiety Worsens Prognosis in Patients With Coronary Artery Disease. Journal of the American College of Cardiology, 49, 2021-2027.

Coelho, R., Ramos, S., Prata, J., Bettencourt, P., \& Ferreira, A. (2005). Heart Failure and Health Related Quality of Life. Clin Pract Epidemiol Ment Health, 1, 19.

Clay, A. (2007). One Heart-Many Threats Psychologists Take on Heart Disease: The Nation's Number One Killer. Monitor on Psychology, 38, 46.

DiMatteo, M. R., Lepper, H. S., \& Croghan T. W. (2000). Depression Is a Risk Factor for Noncompliance with Medical Treatment: Meta-Analysis of the Effects of Anxiety and Depression on Patient Adherence. Archives of Internal Medicine, 160, 2101-2107. http://dx.doi.org/10.1001/archinte.160.14.2101

Duru, F., Büchi, S., Klaghofer, R., Hattmann, H., Sensky, T., Buddeberg, C., \& Candinas, R. (2001). How Different from Pacemaker Patients Are Recipients of Implantable Cardioverter-Desfibrillators with Respect to Psychosocial Adaptation, Affective Disorders, and Quality of Life? Heart, 85, 375-379. http://dx.doi.org/10.1136/heart.85.4.375

Ellis, A., \& Abrahms, E. (2005). Rational Emotive Therpy. México: Pax México.

Esquivel, C., Gámez, J., Villa, F., García, F., Martínez, J., Aguirre, B., \& Velasco, V. (2009). Anxiety and Depression in Acute Coronary Syndrome. Medicrit, 6, 18-23.

Figueroa, C., Domínguez, B., Ramos, B., \& Alcocer, L. (2009). Emergency of the Behavioral Cardiology in the Clinical Practice. Psicología y Salud, 19, 151-155.

García, H., \& Calvanese, N. (2008). Perceived Quality of Life , Depression and Anxiety in Patients with Renal Replacement Therapy. Revista de Psicología y Salud, 18, 5-15.

Green, C., Porter, C., Bresnahan, R., \& Spertus, J. (2000) Development and Evaluation of the Kansas City Cardiomyopathy Questionnaire: A New Health Status Measure for Heart Failure. Journal of American College Cardiology, 35, $1245-1255$. http://dx.doi.org/10.1016/S0735-1097(00)00531-3

General Hospital of México (2011). Statistical booklet, enero-marzo 2011.

http://www.hgm.salud.gob.mx/descargas/pdf/planeacion/cuaderno_ene_mar_11.pdf

Instituto Nacional de Salud Pública (2010). Heart Disease, the Leading Cause of Death in Mexico. http://www.insp.mx/noticias/nutricion-y-salud/1372-enfermedades-cardiacas-primera-causa-de-muerte-en-mexico.html

Ittersum, M., Greef, M., Gelder, I., Coster, J., Brugemann, J., \& Schans, C. (2003). Fear of Exercise and Health-Related Quality of Life in Patients with an Implantable Cardioverter Defibrillator. International Journal of Rehabilitation Research, 26, 117-122. http://dx.doi.org/10.1097/00004356-200306000-00006

Kaya, A., Ozben, B., Demircan, S., Cinar, M., Yilmaz, E., \& Adalet, K. (2006). Depression and Anxiety Status of Patients with Implantable Cardioverter Defibrillator and Precipitating Factors. Pacing and Clinical Electrophysiology, 29, 619626. http://dx.doi.org/10.1111/j.1540-8159.2006.00409.x

Leosdottir, M., Sigurdsson, E., Reimarsdottir, G., Gottskalksson, G., Torfason, B., Vigfusdottir, M., Eggertsson, S., \& Arnar, O. (2006). Health-Related Quality of Life of Patients with Implantable Cardioverter Defibrillators Compared with That of Pacemaker Recipients. Europace, 8, 168-174. http://dx.doi.org/10.1093/europace/euj052

Martijn, J., Van Hemel, N., Kelder, J., Van Den Bos, A., Taks, W., Grobbee, D., \& Moons, K. (2008a). Predictors of Improved Quality of Life 1 Year after Pacemaker Implantation. American Heart Journal, 156, 491-497. 
http://dx.doi.org/10.1016/j.ahj.2008.04.029

Martijn, J., Van Hemel, N., Kelder, J., Van Den Bos, A., Taks, W., Grobbee, D., \& Moons, K. (2008b). Poor Health-Related Quality of Life of Patients with Indication for Chronic Cardiac Pacemaker Therapy. Pacing and Clinical Electrophysiology, 31, 480-486. http://dx.doi.org/10.1111/j.1540-8159.2008.01018.x

Matiz, H., Gutiérrez, O., Duque, M., \& Gómez, A. (1999). Evidence-Based Clinical Practice Guidelines. Colombian Association of Medical Schools, Seguro Social, 51.

Morillo, Z. C., Medina, D. E., Rosas, A. F., \& Cabrales, N. M. (2005). Syncope. Bogotá, Colombia: Sociedad Colombiana de Cardiología y Cirugía Cardiovascular.

Moser, D., \& De Jong, M. (2006). Ansiety and Heart Disease. In Molinari, E., Compare, A., \& Parati, G. (Eds.), Clinical Psychology and Heart Disease (pp. 130-169). Italia: Springer.

Parmet, S., Lynm, C., \& Glass, R. (2002). Depression and Heart Disease. The Journal of the American Medical Association, 288, 792. http://dx.doi.org/10.1001/jama.288.6.792

Sarmiento, J. (2011). Quality of Life, Anxiety and Depression: Comparison of Patients with Heart Failure and LifeThreatening Arrhythmia. Tesis de Licenciatura, México: UNAM.

Secretaria de Salud (2012). Accountability in Health 2010. México http://portal.salud.gob.mx/contenidos/transparencia/rendicion_de_cuentas/pdf/irc_ss_3.pdf

Van den Broek, K., Nyklíček, I., Van der Voort, P., Alings, M., Meijer, A., \& Denollet, J. (2009). Risk of Ventricular Arrhythmia after Implantable Defibrillator Treatment in Anxious Type D Patients. Journal of the American College of Cardiology, 54, 531-537. http://dx.doi.org/10.1016/j.jacc.2009.04.043

Watkins, L., Blumenthal, J., Davidson, J., Babyak, M., McCants, C., \& Sketch, M. (2006). Phobic Anxiety, Depression, and Risk of Ventricular Arrhythmias in Patients. Psychosomatic Medicine, 68, 651-656. http://dx.doi.org/10.1097/01.psy.0000228342.53606.b3

Whang, W., Kubzansky, L., Kawachi, I., Rexrode, K., Kroenke, C., Glynn, R., Garan, H., \& Albert, C. (2009). Depression and Risk of Sudden Cardiac Death and Coronary Heart Disease in Women. Journal of the American College of Cardiology, 13, 950-958. http://dx.doi.org/10.1016/j.jacc.2008.10.060

WHO (2011). http://www.who.int/whosis/whostat/2011/en/

Zigmond, A. S., \& Snaith, R. P. (1983). The Hospital Anxiety and Depression Scale. Acta Psychiatrica Scandinavica, 67, 361-370. http://dx.doi.org/10.1111/j.1600-0447.1983.tb09716.x

Zvolensky, M., \& Smits, J. (2008). Anxiety in Health Behaviors and Physical Illness. USA: Springer. 